\title{
Ethnic Disparities in Utilization of Maternal and Child Health Services in Rural Southwest China
}

\author{
Chaofang Yan ${ }^{1}\left(\mathbb{D}\right.$, Charuwan Tadadej ${ }^{1, *}$, Kanittha Chamroonsawasdi ${ }^{2}{ }^{\mathbb{D}}$, \\ Natkamol Chansatitporn ${ }^{3}$ and John FC Sung ${ }^{4}$ \\ 1 Department of Public Health Administration, Faculty of Public Health, Mahidol University, \\ Bangkok 10400, Thailand; chaofangyan@hotmail.com \\ 2 Department of Family Health, Faculty of Public Health, Mahidol University, Bangkok 10400, Thailand; \\ kanittha.cha@mahidol.ac.th \\ 3 Department of Biostatistics, Faculty of Public Health, Mahidol University, Bangkok 10400, Thailand; \\ nutkamol.cha@mahidol.ac.th \\ 4 Institute of Health and Development Studies, School of Public Health, Kunming Medical University, \\ Kunming 650500, China; fcsung1008@yahoo.com \\ * Correspondence: charuwan.tad@mahidol.ac.th; Tel.: +66-2-644-8833; Fax: +66-2-644-8554
}

Received: 4 November 2020; Accepted: 17 November 2020; Published: 19 November 2020

\begin{abstract}
Background: Studies in China on ethnic disparities in access to health care in remote and rural population remain insufficient. This study aimed to assess the disparities in utilization of maternal and child health (MCH) services, including antenatal care (ANC), hospital birth, child growth monitoring, and immunization compliance between Han and ethnic minority women in Yunnan Province. Methods: A multi-stage sampling scheme was used to randomly recruit women from 40 townships in 14 remote prefectures of extremely remote areas in Yunnan. From birth records, we identified and recruited 303 Han women and 222 ethnic minority women who had given birth to a child within 3 years for an interview. Results: Overall, $96 \%$ of women used the ANC checkups and more than $95 \%$ had infants born in hospitals. However, the proportion of women compliant with early ANC visits (having antenatal care in the first trimester) was $22.5 \%$ lower in minority women than in Han women $(61.3 \%$ vs. $83.8 \%, p<0.001)$ with an adjusted odds ratio (aOR) of 2.04 (95\% confidence interval (CI) of 1.13-3.66) for the minority group. The proportion of children under one year old with immunizations completed in a timely manner was also lower in minority families than in Han families $(80.2 \%$ vs. $86.8 \%, p<0.05)$ with an aOR of $1.99(95 \% \mathrm{CI}=1.16-3.40)$. Conclusions: Ethnic disparities remain in utilization of early ANC visits and timely immunization completion for newborns. Ethnic minority women tended to lag behind for both. Further intervention should focus on assisting minority women living in extremely rural areas to comply with the $\mathrm{MCH}$ policy. Culturally-sensitive policies and skills are needed, and priority should be given to improve utilization of early ANC and timely immunization completion.
\end{abstract}

Keywords: ethnic disparity; utilization; maternal and child health services; China

\section{Introduction}

Women and children are at a crucial position in social development. The United Nations (UN) has highlighted strategies to promote the health of women and children in the Millennium Development Goals (MDG) 4 and 5 from 2000 to 2015, and in Sustainable Development Goal (SDG) 3 from 2016 to 2030. Substantial progress in maternal and child survivals has been made since the 1990s [1]. Timely maternal and child health $(\mathrm{MCH})$ services utilization is vital to reduce both the maternal and child deaths [2-5]. The mediation of the MDG has increased utilization of antenatal care (ANC) services 
to $44 \%$ and assisted delivery to $12 \%$. The UN efforts have thus reduced maternal deaths by $44 \%$ from 283.2 per 100,000 live births in $1990[4,6]$. The coverage for priority interventions among disadvantaged populations in a country is an indication of the strength of the health system [7].

Reducing MCH disparity has been a crucial issue across the whole nation in China, a developing country with the largest population in the world [8-11]. The Chinese government has taken a series of actions in order to increase the coverage of the interventions of $\mathrm{MCH}$ among disadvantaged populations in less developed regions [12-14]. For example, from 1996 to 1999 the government started a World Bank loan program, the Poverty Alleviation Fund for Maternal and Child Health. The program aimed to reduce maternal mortality rate (MMR) and infant mortality rate (IMR) by assisting $5 \%$ of poor families with their payment of the MCH services in five western provinces [12,15]. From 2000 to 2008, the program of Reducing Maternal Mortality and Eliminating Neonatal Tetanus was launched to reduce MMR, mainly targeting 378 counties in rural areas [14]. The Basic Public Health Service (BPHS) project, launched in 2009, is one of the most effective policies for providing and promoting residents with equal access to basic public health services. This government-funded project includes nine service categories, including one reform to improve $\mathrm{MCH}$ services $[13,16]$. After years of effort, the urban-rural disparity of MMR in China has been greatly narrowed. The urban-to-rural ratio of MMR reduced from 1:2.2 in 1990 to 1:1.3 in 2018 (15.5 vs. 19.9 deaths per 100,000 livebirths) [10]. The western part of China is less developed than the eastern part of China; the eastern-to-western region ratio of MMR reduced from 1:4.7 in 1996 to 1:2.3 (10.9 vs. 25.2 per 100,000 livebirths) in 2018. The project also reduced the urban-rural ratio of the under-5 mortality from 1:3.4 in 1991 to 1:2.3 in 2018 (4.4 vs. 10.2 per 1000 livebirths). The gap in under-5 mortality rates between east and west regions was reduced to $8.5 \%$ in 2018 from $66.5 \%$ o in 1991 [10].

The MCH disparities between east and west China, or between urban and rural, have been explored and well documented. However, studies evaluating the ethnic disparities with robust methods remain severely insufficient in China [17]. The Lancet-Lowitja Institute Global Collaboration study has shown that Yunnan province and Tibet Autonomous Region in China have not yet reached the UN SDG for underserved populations [18]. Some studies related to ethnic populations have reported health coverage and health outcomes based on the whole population from the Autonomous Region rather than classified by ethnic type [8,19]. No study has compared differences of MCH between Han and ethnic minorities at a provincial level, because the medical records and vital statistics were rarely classified by ethnicity in the official health statistics system. Most studies have emphasized the improvement of health data collection for ethnic minorities in China $[17,18,20]$.

China is populated with multiple ethnic groups with high cultural and language diversities; these consist of the Han majority accounting for $91.5 \%$ of the total population and 55 minority groups accounting for the rest of the population (8.5\%). The 2010 census estimated that 114 million people in China were ethnic minorities. Three-quarters $(71.4 \%)$ of all ethnic minorities live in the remote southern and western regions of China, including Yunnan Province [21].

Yunnan Province is located in Southwestern China, bordering Myanmar in the west, and Laos and Vietnam in the south. It is one of the poorest remote provinces and has the highest ethnic diversity in China (Figure 1), including 8 ethnic autonomous prefectures and 29 ethnic autonomous counties. Among 56 recognized ethnic groups in China, Yunnan Province has recognized at least 25 ethnic minority groups, making up $33.6 \%$ of the 48 million population in the province in 2018 . Yunnan is situated in mountainous land, with only $6 \%$ of plain areas suitable for cultivation [22]. The provincial authority has endeavored to carry out the ambitious provincial goal since 2010 for reducing MMR to 25/100,000 and IMR to 11 per 1000 live births by 2020, then reducing the MMR to 12/100,000 and the IMR to 5 per 1000 live births by 2030, based on the MMR 37.3/100,000 and the IMR 15.2 per 1000 live births in 2010 [23,24]. For better utilization of MCH services, pregnant women are officially encouraged to complete at least five ANC with the first ANC in the first trimester, hospital delivery, having their children under one year old checked for growth monitoring at least four times, and getting their children vaccinated in a timely manner according to the National Immunization Program [25]. 


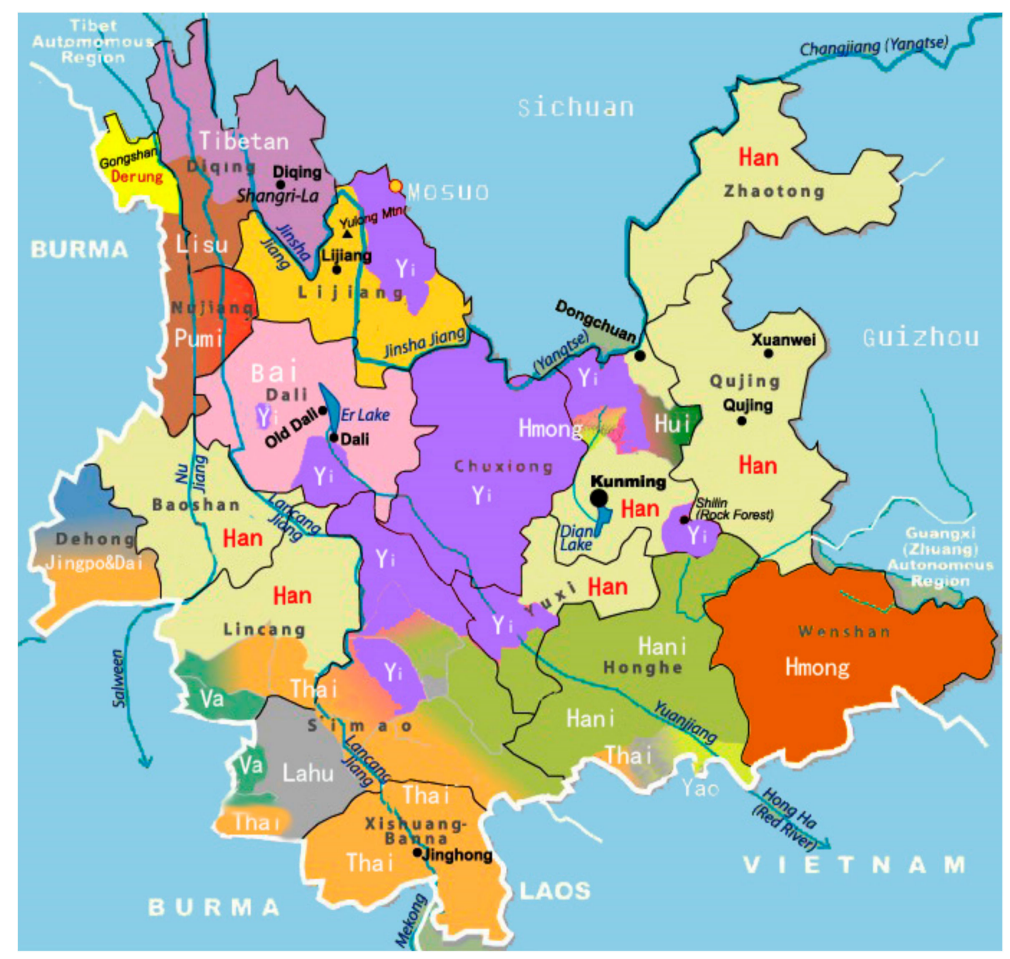

Figure 1. Ethnic diversity of Yunnan Province, China.

As a province with typical ethnic minorities, no study has yet compared the compliance of $\mathrm{MCH}$ care services between Hans and ethnic minorities in Yunnan. Therefore, we conducted a survey in remote rural areas in the province to assess the disparities in utilization of $\mathrm{MCH}$ services between Han and the ethnic minority mothers.

\section{Materials and Methods}

\subsection{Study Design and Participants Recruitment}

This study was a cross-sectional survey with a comparison between Han and ethnic minorities. Women who had given birth within the past three years at the time of the survey and had been residing in the selected township in Yunnan for at least three years were included in the study. This inclusion criteria ensured that these women could provide the health service information for both mothers and children, such as the information of growth monitoring and immunization. Women who worked and used health services out of the selected township were excluded to show the effect of ethnicity in the same context. A conceptual framework, adapted from the model of access to medical care by Andersen [26], was used to examine the access to $\mathrm{MCH}$ services and to analyze the factors affecting access to MCH services.

The sample size was calculated based on detecting a significant proportional difference of hospital births between ethnic minorities and the Han group at a $5 \%$ level with $80 \%$ power of a two-sided test. Previous studies in Yunnan Province have reported that the hospital birth rates were 81\% (512/631) in minority women and $91 \%(476,132 / 523,223)$ in Han women $[27,28]$. These data were used to calculate the minimum sample size being at least 188 subjects in each group for this study.

A multi-stage sampling method was used to select the study sample. Firstly, we excluded the provincial capital Kunming to eliminate the effects of economic inequality and Nujiang prefectures that are difficult to reach by automobile transportation. For the rest of the 14 prefectures, 1 county was randomly selected from each prefecture. In each selected county, after excluding the township in which the county government was located, we randomly selected a township. Based on the birth 
records from the township hospital in the selected township, 40 women with a birth within the past three years at the time of the survey were randomly selected from each township, resulting in a total of 560 women selected as potential participants. For participants with more than one pregnancy and delivery, information from the last pregnancy was collected and used.

This study was approved by the ethics committee of the Faculty of Public Health, Mahidol University (COA No. MUPH 2014-214; 24 November 2014). All participants were clearly informed of their rights and any risks associated with participation. Verbal consent was obtained from all interview participants.

\subsection{Study Procedure and Data Collection}

We applied the Andersen health behavior model to establish a structured questionnaire for data collection of the survey to investigate $\mathrm{MCH}$ services associated with predisposing (demographic and social) factors, enabling (economic) factors, and need (health outcomes) factors [26]. The questionnaire was reviewed by experts in $\mathrm{MCH}$, social medicine, and health management.

The questionnaire asked for four types of information. The first type regarded predisposing factors including the general characteristics of respondents, comprising age of the woman, age of the child, sex of the child, parity, ethnicity, language ability, education, and knowledge on MCH. The second part regarded enabling factors: the family income, family size and health insurance, the usual health facility, and travel time to the nearest health facility for childbirth. The third part regarded need factors: the woman's health status during the perinatal period, previous obstetric problems, child health status, preterm delivery, and birth weight of the child. The fourth part asked for information about $\mathrm{MCH}$ utilization, including ANC utilization, timing for ANC visits, hospital birth, delivery type, child growth monitoring services, timing for child growth monitoring visits, and immunization services.

Before the actual data collection, the questionnaire was pre-tested on 20 women from villages of the study area. The reliability of scaling variables was assessed by calculating Cronbach's coefficient alpha $(\alpha=0.716)$, which indicated that the measures had fairly high levels of reliability. The questionnaire was administered in person by trained interviewers at each participant's household. We trained 32 medical students who could speak the local dialog as interviewers. A two-day interview workshop was given to them before conducting the survey.

After excluding 22 women who refused interviews and 13 women who could not complete the questionnaires, information was obtained from 525 households in total. The ethnic minorities included 15 ethnicity groups of Yi, Hani, Thai, Zhuang, Hmong, Bai, Yao, Hui, Lisu, Va, Lahu, Nu, Jingpo, Achang, and Paijiao.

\subsection{Statistical Analysis}

Eligible questionnaires were edited and coded, and the data were entered and processed using SPSS version 19. Data analysis first compared distributions of participants' characteristics in predisposing factors, enabling factors, and need factors between Han and ethnic minority participants. Utilization of $\mathrm{MCH}$ care (ANC visit, infant delivery, growth monitoring, and immunization) was presented by numbers and proportions. Chi-square test was used to examine the difference between the two groups. Logistic regression analysis was further used to calculate odds ratio (OR) and 95\% confidence interval (CI) of inadequate utilization of $\mathrm{MCH}$ care for the ethnic minority women, compared to Han women. The adjusted odds ratio (aOR) was estimated with a multivariable by three models: after controlling for predisposing factors, after controlling for predisposing and enabling factors, and after controlling for predisposing, enabling, and need factors.

\section{Results}

\subsection{Socio-Demographic Profile}

With response rates of $97.1 \%$ and $89.5 \%$ in Han and ethnic minorities, respectively, 303 Han women and 222 minority women completed the questionnaire interviews. The average ages of participants in 
both Han and ethnic minority groups were approximately similar at 26 years old. The Han group had higher education and better Mandarin language ability, with higher income, than the ethnic minority group. Ethnic minority women were more likely $(69.4 \%)$ to be married to ethnic minority husbands (refer to Husband's Ethnicity type) than were Han women (8.3\%), and they had a larger family size than Han women did. Ethnic minority women needed more travel time to reach their nearest health care facility and perceived that their children had a poor health status. (Table 1).

Table 1. Sociodemographic characteristics of study subjects in Yunnan.

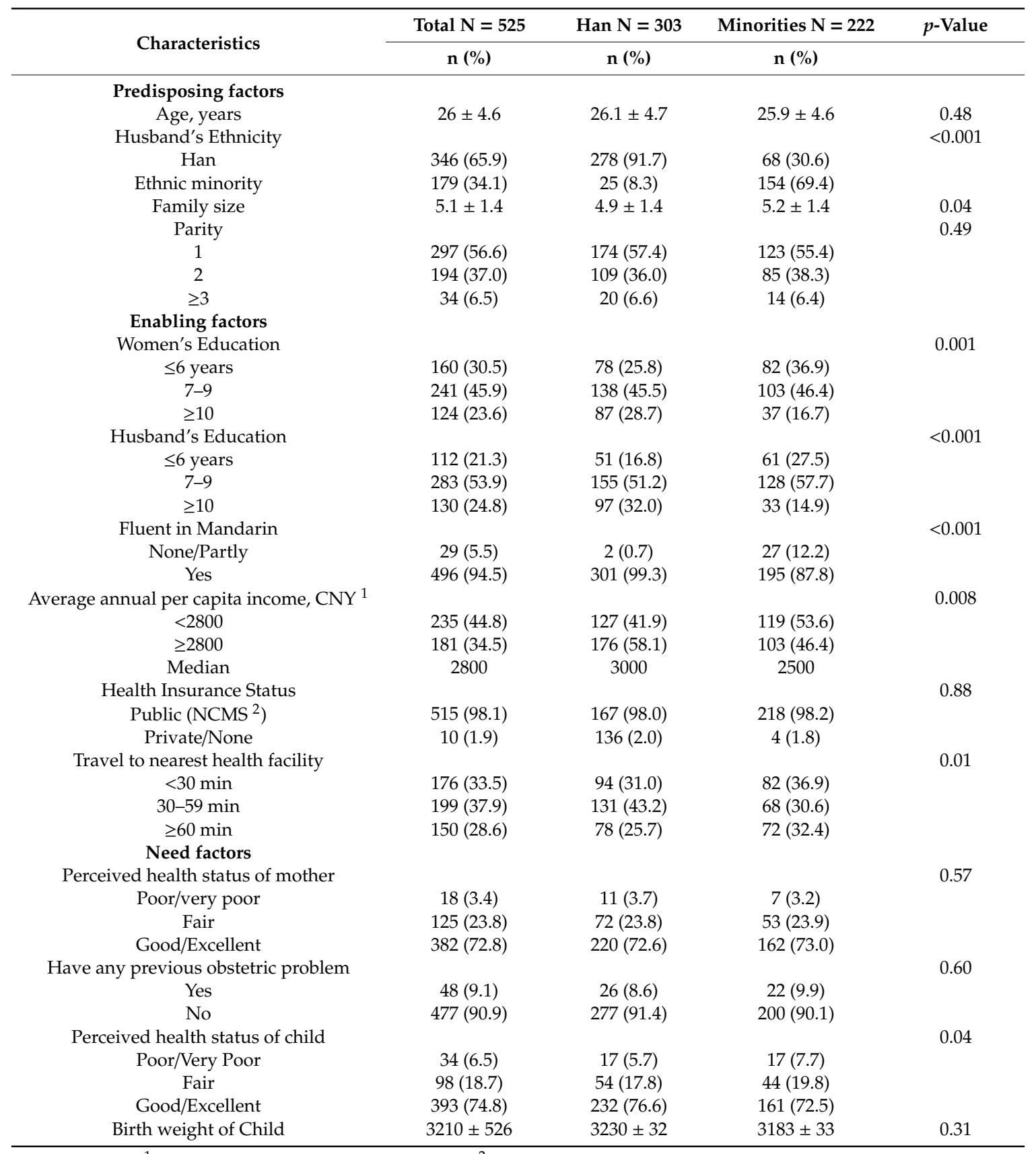

${ }^{1} \mathrm{CNY}$, Chinese yuan, 1 USD = $6.2 \mathrm{CNY}{ }^{2} \mathrm{NCMS}$, New rural cooperating medical scheme.

\subsection{Comparison of MCH Utilization}

More than $90 \%$ of women had at least one ANC visit and nearly $60 \%$ made five visits during their pregnancy (Table 2). The Han women had a higher adherence to the recommended 5-visit schedules than did ethnic minority women by making their first ANC visit in the first trimester (58.1\% vs. $43.2 \%$, 
$p<0.001)$. However, making an early ANC visit was $22.5 \%$ lower in minority women than in Han women ( 61.3 vs. $83.8 \%$ ). Over $95 \%$ of participants had their infants delivered at health institutions, with a higher incidence of Caesarean delivery in Han women ( $26.1 \%$ vs. $20.3 \%$, p 0.12$)$. However, a lower proportion of ethnic minority women completed the required vaccinations for children within the first year of age than Han women $(80.2 \%$ vs. $86.8 \%, p<0.05)$.

Table 2. Comparison on utilization of maternal and child health care between Han and ethnic minority women.

\begin{tabular}{|c|c|c|c|c|c|}
\hline \multirow{2}{*}{ Type of $\mathrm{MCH}^{1}$ Services } & $\begin{array}{c}\text { Total } \\
N=525\end{array}$ & $\begin{array}{c}\text { Han } \\
\mathbf{N}=303\end{array}$ & $\begin{array}{c}\text { Minorities } \\
\mathrm{N}=222\end{array}$ & $\mathrm{X} 2$ & $p$ \\
\hline & n $(\%)$ & n $(\%)$ & n $(\%)$ & & \\
\hline \multicolumn{6}{|l|}{ Antenatal care } \\
\hline $\mathrm{ANC}^{2}$ at least 1 visit & $504(96.0)$ & $297(98.0)$ & $207(93.2)$ & 7.61 & $<0.05$ \\
\hline ANC at least 5 visits & $318(60.6)$ & $192(63.4)$ & $126(56.8)$ & 2.34 & 0.13 \\
\hline Early ANC visit ${ }^{3}$ & $390(74.3)$ & $254(83.8)$ & $136(61.3)$ & 27.38 & $<0.001$ \\
\hline $\begin{array}{c}\text { ANC at least } 5 \text { visits with an early ANC } \\
\text { visit }\end{array}$ & $272(51.8)$ & $176(58.1)$ & $96(43.2)$ & 11.3 & $<0.05$ \\
\hline \multicolumn{6}{|l|}{ Hospital births } \\
\hline Hospital birth & $503(95.8)$ & $292(96.4)$ & $211(95.0)$ & 0.56 & 0.45 \\
\hline Caesarean Delivery & $124(23.6)$ & $79(26.1)$ & $45(20.3)$ & 2.39 & 0.12 \\
\hline $\begin{array}{l}\text { Growth monitoring services for children } \\
\text { within the first year of age }\end{array}$ & $231(44.0)$ & $126(41.6)$ & $105(47.3)$ & 1.70 & 0.19 \\
\hline $\begin{array}{l}\text { Use at least } 4 \text { times } \\
\text { Immunization }\end{array}$ & $231(44.0)$ & $126(41.6)$ & $105(47.3)$ & 1.70 & 0.19 \\
\hline Vaccinated all doses & $520(99.0)$ & $300(99.0)$ & $220(99.1)$ & 0.01 & 0.91 \\
\hline Vaccinated all doses timely & $441(84.0)$ & $263(86.8)$ & $178(80.2)$ & 4.18 & $<0.05$ \\
\hline
\end{tabular}

\subsection{Odds Ratio of MCH Services Utilization}

Table 3 shows that, compared with the Han women, the minority women were at higher risks for inadequate antenatal care, with significant unadjusted ORs of $3.59(95 \% \mathrm{CI}=1.37-9.40)$ for failing to make at least one ANC visit during the pregnancy, of $3.28(95 \% \mathrm{CI}=2.00-4.75)$ for failing to make an early ANC visit in the first trimester, and of $1.82(95 \% \mathrm{CI}=1.28-2.58)$ for failing to make at least 5 ANC visits with an early ANC visit in the first trimester. However, only the risk of failing to make an early ANC visit remained significant after controlling for predisposing, enabling, and need factors, with an aOR of $2.04(95 \% \mathrm{CI}=1.13-3.66)$. The ethnic minorities were also at a higher risk of not receiving vaccinations for children with all doses in a timely manner, with an aOR of $1.99(95 \% \mathrm{CI}=1.16-3.40)$ after controlling for all covariables. 
Table 3. Ethnic minority women compared to Han women odds ratio (OR) of inadequate MCH utilization and adjusted odds ratio (aOR) controlling for predisposing, enabling, and need factors.

\begin{tabular}{|c|c|c|c|c|}
\hline Type of MCH Services & $\begin{array}{l}\text { Base Model, } \\
\text { OR }(95 \% \text { CI) }\end{array}$ & $\begin{array}{l}\text { Predisposing Factors } \\
\text { Model, OR (95\% CI) }\end{array}$ & $\begin{array}{l}\text { Predisposing-Enabling } \\
\text { Factors Model, OR (95\% CI) }\end{array}$ & $\begin{array}{l}\text { Predisposing-Enabling-Need } \\
\text { Factors Model, OR }(95 \% \mathrm{CI})\end{array}$ \\
\hline \multicolumn{5}{|l|}{ Antenatal care } \\
\hline ANC at least 1 visit & $3.59(1.37-9.40) *$ & $1.80(0.51-6.31)$ & $1.62(0.36-7.38)$ & $1.88(0.42-8.51)$ \\
\hline ANC at least 5 visits & $1.32(0.93-1.88)$ & $0.96(0.60-1.53)$ & $0.97(0.59-1.60)$ & $1.01(0.61-1.67)$ \\
\hline Early ANC visit & $3.28(2.00-4.75) *$ & $1.81(1.05-3.15) *$ & $1.91(1.07-3.41) *$ & $2.04(1.13-3.66)$ * \\
\hline $\begin{array}{c}\text { ANC at least } 5 \text { visits with an early ANC visit } \\
\text { Hospital birth }\end{array}$ & $1.82(1.28-2.58)$ * & $1.27(0.81-2.00)$ & $1.34(0.83-2.17)$ & $1.42(0.87-2.32)$ \\
\hline Hospital birth & $1.38(0.59-3.25)$ & $1.00(0.32-3.14)$ & $0.90(0.23-3.90)$ & $0.95(0.25-3.66)$ \\
\hline Caesarean Delivery & $0.72(0.48-1.09)$ & $0.71(0.42-1.23)$ & $0.76(0.44-1.31)$ & $0.77(0.44-1.33)$ \\
\hline \multicolumn{5}{|l|}{$\begin{array}{l}\text { Growth monitoring services for children } \\
\text { within the first year of age }\end{array}$} \\
\hline Use at least 4 times & $0.79(0.56-1.12)$ & $0.70(0.44-1.10)$ & $0.65(0.41-1.05)$ & $0.65(0.41-1.05)$ \\
\hline \multicolumn{5}{|l|}{ Immunization services } \\
\hline Vaccinated all doses & $0.91(0.15-5.49)$ & $1.68(0.21-13.6)$ & $2.47(0.19-31.4)$ & $2.47(0.20-31.0)$ \\
\hline Vaccinated all doses timely & $1.63(1.02-2.60)$ * & $1.73(1.03-2.89)$ * & $1.79(1.06-3.04)$ * & $1.99(1.16-3.40)$ * \\
\hline
\end{tabular}

Note: The Predisposing Factors Model controlled for husband ethnicity and family size. Predisposing-Enabling Factors Model controlled for husband ethnicity, family size, education, husband education, Mandarin language ability, income, and travel time. The Predisposing-Enabling-Need Factors Model controlled for husband ethnicity, family size, education, husband education, Mandarin language ability, income, travel time, and perceived child health, which were significant predictors. ${ }^{*} p<0.05$. 


\section{Discussion}

This study aimed to assess the disparities in the utilization of MCH services between Han and ethnic minority mothers in remote rural areas. Theoretically, minority women and Han women could receive similar care even in the remote rural areas. We found that gaps of using $\mathrm{MCH}$ services still existed in ANC utilizations, significant for the early ANC visit in the mountainous rural region of Yunnan. The pregnant women from minority families were less likely than Han women to make the first ANC within the first 12 gestational weeks. Previous studies have rarely measured the disparities between the Han and ethnic minority populations in pregnancies, although some studies have reported the rates of the early ANC visits related to ethnic minority population in other provinces [29-33]. The timing of the first antenatal care visit is an important compliance measure to ensure optimal pregnancy outcomes for women and children $[4,34]$. The early antenatal care visit also has been used as an indicator to measure the quality of $\mathrm{MCH}$ services since launching the health care reform in 2009 in China [25]. This finding might imply the need of exploring the cultural factors for early ANC visits among ethnic minority women. Our study also showed the need to develop additional culture-sensitive policy to eliminate inequality and deliver cost effective $\mathrm{MCH}$ interventions.

Further, compared to Han mothers, the ethnic minority mothers were also less likely to have their children immunized in a timely manner, which is crucial for preventing childhood diseases. Studies have consistently reported a poor compliance with immunization services for children of ethnic minorities in China $[17,35-37]$. With an investment of USD $\$ 120$ billion, the universal health insurance coverage increased to $95 \%$ of the population in 2019 from 30\% in 2003 [38]. The economic barriers to accessing ANC, hospital births, and immunization services for rural populations have been removed, yet disparities were still observed.

This study found that hospital birth and caesarean delivery between Han and ethnic minority women were not significantly different. This was likely because of the compliance to the UN's MDG and SDG strategies to promote the health of women and children. In China, like many developing countries, the economic level plays an important role in health service accessibility, especially in remote rural areas where many ethnic minorities live. Over the past 20 years, the Chinese Government has introduced several strategies aimed specifically at reaching underserved populations in rural areas. In 2003, a voluntary health insurance program, New Cooperative Medical Scheme (NCMS), was launched for rural residents. This heavily subsidized program has increased outpatient and inpatient services utilization by reducing the health service cost with a sliding fee discount of $30 \%$ to $80 \%$, varying by region annually [39,40]. In addition to the major support from the central authority, some of the local health administrations also received support from international organizations such as the United Nations International Children's Emergency Fund (UNICEF) $[12,15,41]$. The administrations were thus capable of conducting pilot studies using poverty alleviation funds to help low income pregnant women adhere to $\mathrm{MCH}$ services in a timely manner in some identified poverty-stricken counties.

Similarly, there were also no significant differences in using service of growth monitoring for children under 1 year old between Han and ethnic minority families in this study. The BPHS project of new medical reform policies has made a great contribution to promoting equal access to basic public health services since it was launched in 2009 [42]. This government-funded project included nine service categories, one of which was to improve infant cares. The project encouraged all families having their children under 1 year old to complete "four times-routine examination at the 3, 6, 8, and 12 months of age" to monitor growth and development free of charge. Further, all MCH physicians are required to have standardized training and to deliver the same maternal services for rural and urban populations [25].

As a whole, we demonstrated a substantial improvement in utilization of $\mathrm{MCH}$ services among all women in this study compared with the utilizations in the 1990s, providing valid information on the improvement of $\mathrm{MCH}$ services in remote rural areas. Overall, $96 \%$ of pregnant women used the antenatal checkups at least once in the present study, compared to $58.07 \%$ in 1992 in the whole Yunnan 
province. The compliance with at least five antenatal checkups improved to $60.6 \%$ from $23.78 \%$ in 1992. The greatest improvement is that the hospital birth increased to $95.8 \%$ from only $30.33 \%$ in 1990. More importantly, vital statistics data showed the MMR had a great decline from 115.29 per 100,000 livebirths in 1992 to 17.72 per 100,000 livebirths in 2018, and the infant mortality rates declined from $46.38 \%$ o in 1992 to $5.85 \%$ o in 2018 in Yunnan Province [43,44]. All the policies such as the NCMs and BPHS contribute to this great progress. The Targeted Poverty Alleviation Project was recently launched to further increase accessibility to local health care without charge for families officially registered as Poverty-Stricken Households [45]. We anticipate this effort will further reduce the ethnic disparities in $\mathrm{MCH}$ services utilization in rural China. However, most current policies tend to invest more money to reduce health inequality but have less emphasis on cultural barriers, transportation barriers, and development of the health workforce in extremely rural areas [46,47]. Minority women living in these areas deserve further intervention if the highest ethnic diversity province wants to reach the goals of MMR of 12/100,000 and the IMR of 5 per 100 live births by 2030 [24].

This study has a few limitations. This study excluded women who had experienced an abortion or had children who died under the age of 3 years. Their utilization of MCH services is not clear. Among the 560 women randomly invited to participate in this study, 35 women were not interviewed. These women were less likely to be compliant with required $\mathrm{MCH}$ checkups, and their information was not included in this study. Furthermore, information on $\mathrm{MCH}$ services was collected from women within 3 years of the childbirth at the time of survey, the self-reported data throughout the period might vary slightly among women. However, interviewers conducted the survey following strict protocols. The response bias was likely unintentional and would not adversely affect the survey outcome.

\section{Conclusions}

This study found that gaps of using $\mathrm{MCH}$ services between ethnic minorities and Han women exist in ANC utilization and timely immunization completion in China. Ethnic minority women tended to lag behind in utilization of early ANC, and in timely immunization completion for their children under one year old. However, there were no significant differences in hospital birth, caesarean delivery, and growth monitoring for children under 1 year old between Han and ethnic minority women in this study. China's political commitment to poverty reduction for compliance with the UN MDG and SDG might have contributed to the improvement. A heavily subsidized NCMS and the BPHS of new medical reforms might also play an important role in promoting equal access to $\mathrm{MCH}$ services. Minority women living in extremely rural areas deserve further intervention. Culturally-sensitive policies and skills are needed to target ethnic populations to improve their access to $\mathrm{MCH}$ services in order to continue decreasing the urban-rural and ethnic disparities. Priority should be given to improve utilization of early ANC and timely immunization completion.

Author Contributions: C.Y. designed the study, analyzed data, interpreted findings, and drafted the manuscript. C.T. provided supervision in the development of the study concept and design, advised on the scope of the paper, and provided critical revision of the manuscript. K.C. advised on the study theory and revised the manuscript critically. N.C. advised on sampling and data analysis methods and revised the manuscript critically. J.F.S. assisted in study design and data presentation and revised critically the manuscript for important intellectual content. All authors have read and agreed to the published version of the manuscript.

Funding: This research received no external funding.

Acknowledgments: We are thankful to health officers, rural physicians and medical students from Kunming Medical University in Yunnan, China, for their great assistance in this study. This article is a fulfillment of the requirements for a Doctoral study in Public Health, Mahidol University, Bangkok, Thailand, supported by the grant of International Fellowships Program of Ford Foundation (Grant ID:15090343).

Conflicts of Interest: The authors declare that they have no competing interests. 


\section{Abbreviations}

$\begin{array}{ll}\text { aOR } & \text { adjusted odds ratio } \\ \text { ANC } & \text { antenatal care } \\ \text { BPHS } & \text { basic public health service } \\ \text { CI } & \text { confidence interval } \\ \text { IMR } & \text { infant mortality rate } \\ \text { MCH } & \text { maternal and child health } \\ \text { MDG } & \text { Millennium Development Goal } \\ \text { MMR } & \text { maternal mortality rate } \\ \text { NCMS } & \text { New Cooperative Medical Scheme } \\ \text { OR } & \text { odds ratio } \\ \text { SDG } & \text { Sustainable Development Goal } \\ \text { UNICEF } & \text { United Nations International Children's Emergency Fund }\end{array}$

\section{References}

1. WHO; UNICEF; UNFPA; World Bank Group and the United Nations Population Division. Trends in Maternal Mortality: 2000 to 2017; World Health Organization: Geneva, Switzerland, 2019.

2. Spinelli, A.; Baglio, G.; Donati, S.; Grandolfo, M.E.; Osborn, J. Do antenatal classes benefit mother and her baby? J. Matern. Fetal Neonatal Med. 2003, 13, 94-101. [CrossRef] [PubMed]

3. WHO; UNICEF; UNFPA; The World Bank and the United Nations Population Division. Trends in Maternal Mortality: 1990 to 2013; World Health Organization: Geneva, Switzerland, 2014.

4. Moller, A.B.; Petzold, M.; Chou, D.; Say, L. Early antenatal care visit: A systematic analysis of regional and global levels and trends of coverage from 1990 to 2013. Lancet Global Health 2017, 5, e977-e983. [CrossRef]

5. Templeton, A. The Public Health Importance of Antenatal Care. Facts Views Vis. Obgyn 2015, 7, 5-6.

6. Alkema, L.; Chou, D.; Hogan, D.; Zhang, S.; Moller, A.-B.; Gemmill, A.; Fat, D.M.; Boerma, T.; Temmerman, M.; Mathers, C.; et al. Global, Regional, and National Levels and Trends in Maternal Mortality Between 1990 and 2015, With Scenario-based Projections to 2030. Obstet. Anesthesia Dig. 2016, 36, 191. [CrossRef]

7. Bryce, J.; Terreri, N.; Victora, C.G.; Mason, E.; Daelmans, B.; Bhutta, Z.A.; Bustreo, F.; Songane, F.; Salama, P.; Wardlaw, T. Countdown to 2015: Tracking intervention coverage for child survival. Lancet 2006, 368, 1067-1076. [CrossRef]

8. Ren, Y.; Zhao, Z.; Pan, J.; Qian, P.; Duan, Z.; Yang, M. Ethnic disparity in maternal and infant mortality and its health-system determinants in Sichuan province, China, 2002-2014: An observational study of cross-sectional data. Lancet 2017, 390, S7. [CrossRef]

9. Guo, Y.; Huang, Y. Realising equity in maternal health: China's successes and challenges. Lancet 2019, 393, 202-204. [CrossRef]

10. National Health Commission of the People's Republic of China. Report on the development of maternal and child health in China. Chin. J. Women Child. Health 2019, 10, 1-8.

11. Guo, Y.; Yin, H. Reducing child mortality in China: Successes and challenges. Lancet 2016, 387, $205-207$. [CrossRef]

12. Liu, F.Y.; Zhu, X.X.; Yang, L.; Guo, G.P.; Zhou, H.; Li, Z. The Implementation and effect of World Bank Loan Health Project in Yunnan province. Matern. Child Health Care China 2002, 17, 403-406.

13. Zhao, P.; Diao, Y.; You, L.; Wu, S.; Liu, Y. The influence of basic public health service project on maternal health services: An interrupted time series study. BMC Public Health 2019, 19, 1-8. [CrossRef] [PubMed]

14. Liang, J.; Zhu, J.; Wang, Y.; Li, M. Factors of Reducting the Maternal Mortality in counties implementing project of "Reduce maternal mortality and eliminate neonatal tetanus". Chin. J. Epidemiol. 2007, 28, 746-748.

15. Chen, L.; Pei, H.; Huo, L. The Sustainable Development of Poverty Alleviation Fund for Maternal and Child Health in China. Matern. Child Health Care China 2002, 23, 87-89.

16. Wang, F.; Li, Y.; Ding, X.; Dai, T. The national essential public health services project in China: Progress and equity. Chin. J. Health Policy 2013, 6, 9-14.

17. Huang, Y.; Shallcross, D.; Pi, L.; Tian, F.; Pan, J.; Ronsmans, C. Ethnicity and maternal and child health outcomes and service coverage in western China: A systematic review and meta-analysis. Lancet Glob. Health 2018, 6, e39-e56. [CrossRef] 
18. Anderson, I.; Robson, B.; Connolly, M.; Al-Yaman, F.; Bjertness, E.; King, A.; Tynan, M.; Madden, R.; Bang, A.; Coimbra, C.E., Jr.; et al. Indigenous and tribal peoples' health (The Lancet-Lowitja Institute Global Collaboration): A population study. Lancet 2016, 388, 131-157. [CrossRef]

19. Duan, M.F.; Zhou, Y.B.; Li, H.T.; Gao, Y.Q.; Zhang, Y.L.; Luo, S.S.; Kang, C.Y.; Liu, J.M. The rate of hospital births in regions inhabited by ethnic minorities China from 1996 to 2017. Chin. Med. J. 2019, 99, 2135-2140.

20. Stephens, C.; Porter, J.; Nettleton, C.; Willis, R. Disappearing, displaced, and undervalued: A call to action for Indigenous health worldwide. Lancet 2006, 367, 2019-2028. [CrossRef]

21. National Bureau of Statistics. China Statistical Yearbook 2016; China Statistics Press: Beijing, China, 2016.

22. Yunnan Provincial Government. Polulation and Ethnicity of Yunnan Province. Available online: http: //www.yn.gov.cn/yngk/gk/201904/t20190403_96251.html (accessed on 4 November 2020).

23. National Working Committee on Children and Women under State Council of the People's Republic of China. A bulletin on "The Program of Yunan's Women Development (2011-2020)" and "The Program of Yunan's Children Development (2011-2020)“. Available online: http://www.nwccw.gov.cn/node_2502.html (accessed on 4 November 2020).

24. People's Government of Yunnan Province. An Outline for the "Healthy Yunnan 2030" Initiative. Available online: http:/www.yn.gov.cn/zwgk/zcwj/qtwj/201911/t20191101_183998.html (accessed on 4 November 2020).

25. Health Ministry of China. The Outline of Basic Public Health Services Project in China; People's Medical Publishing House: Beijing, China, 2012.

26. Andersen, R.M. Revisiting the Behavioral Model and Access to Medical Care: Does It Matter. J. Health Soc. Behav. 1995, 36, 1-10. [CrossRef]

27. He, G. Analysis of Hospital Delivery rate and it factors in DeQin County, Yunnan Province China. Health Horiz. Med. Sci. 2012, 2, 175.

28. Yu, Y. The rethinking about promoting safe childbirth in poor and remote rural Yunnan. Soft Sci. Health 2012, 26, 386-388.

29. An, L.; Gao, Y.; Zhang, J. Study on the influent factors of antenatal examination in West Poor Rural Areas of China. Chin. J. Reprod. Health 2004, 15, 146-149.

30. Lei, P.; Duan, C.G.; Zhuo-Chun, W.U.; Li, C.; Yu, L.J.; Li, X.H.; Xu, L.; Liu, Y.; Liu, M.W.; Liu, Y.G.; et al. Evaluation of Qinba Health Program: Its impact on antenatal care utilization. Chin. Health Resour. 2010, 13, 64-66.

31. Ren, Z. Utilisation of antenatal care in four counties in Ningxia, China. Midwifery 2011, 27, e260-e266. [CrossRef]

32. Liu, C.; Zhang, L.; Shi, Y.; Zhou, H.; Medina, A.; Rozelle, S. Maternal health services in China's western rural areas: Uptake and correlates. China Agric. Econ. Rev. 2016, 8, 250-276. [CrossRef]

33. Tan, L.F.; Huang, C.L.; Yang, R.R.; Zheng, X.Y. Study on the accessibility of maternal health services for Tibetan women in agricultural and pastoral areas in Yushu Autonomous Prefecture. Matern. Child Health Care China 2012, 27, 325-328.

34. Razum, O.; Breckenkamp, J.; Borde, T.; David, M.; Bozorgmehr, K. Early antenatal care visit as indicator for health equity monitoring. Lancet Glob. Health 2018, 6, e35. [CrossRef]

35. Qi, H.Y.; Fan, J.L.; Zhang, X.L.; Yao, K.L.; Zhang, H.S.; Shi, M.F.; Hou, C.X. Survey and analysis of vaccine inoculation rate of National Immunization Programs in Linxia Prefecture of Gansu Province. Bull. Dis. Control Prev. 2015, 30, 13-17.

36. Zhou, J.; Tang, G.P.; Li, Z.Y.; Deng, J.; Wu, G.G.; Tian, X.G. Investigation on children immunization coverage rate of hepatitis B vaccine and the influential factors. Mod. Prev. Med. 2007, 34, 1444-1447.

37. Lin, Z.; Wang, Q.; Zhang, S.; Wu, J.; Zhou, Y. Association between timely immunization of hepatitis B vaccine and the completion of the national immunization program vaccine. China Trop. Med. 2017, 17, 485-488.

38. National Healthcare Security Administration. Bulletin for HealthCare Statistics in 2019. Available online: http://www.nhsa.gov.cn/art/2020/3/30/art_7_2930.html (accessed on 4 November 2020).

39. Li, L. The New Cooperation Medical System in China; People's Publishing House: Beijing, China, 2009.

40. Xin, Y.; Xiang, L.; Jiang, J.; Lucas, H.; Tang, S.; Huang, F. The impact of increased reimbursement rates under the new cooperative medical scheme on the financial burden of tuberculosis patients. Infect. Dis. Poverty 2019, 8, 67. [CrossRef] [PubMed] 
41. Ministry of Commerce of the People's Republic of China, The United Nations System in China. Excellence in Poverty Reduction: Case Study on China-UN Poverty Reduction Collaboration in the Last Forty Years; China Commerce and Trade Press: Beijing, China, 2019.

42. Health Ministry of China. A Bulletin on "National Standards for Basic Public Health Services". Available online: http://www.nhc.gov.cn/jws/s3581r/200910/fe1cdd87dcfa4622abca696c712d77e8. shtml (accessed on 19 November 2020).

43. People's Government of Yunnan Province. Report on Maternal and Child Health in Yunnan Province. Available online: http://m.yunnan.cn/system/2019/10/15/030399105.shtml (accessed on 4 November 2020).

44. Yu, Y.; Zhao, Z.; Liu, H.; Liu, J. The trend of maternal mortality ratio in yunnan province from 1987 to 2016 and the evaluation of the implementation of the millennium development goals. Chin. Matern. Child Health Care 2018, 33, 8-11.

45. National Health Commission of the People's Republic of China. Guidelines on the Implementation of the Health Poverty Alleviation Project. Available online: http://www.gov.cn/xinwen/2016-06/21/content_5084195. html (accessed on 4 November 2020).

46. Zhu, X.L.; Chen, Q.K.; Yang, S.X. The current situation and problems of primary health care personnel since the new round of China's health care reform. Chin. J. Health Policy 2015, 8, 57-62.

47. Gao, Y.; Zhou, H.; Singh, N.S.; Powell-Jackson, T.; Nash, M.S.; Yang, M.; Guo, S.; Fang, H.; Alvarez, M.M.; Liu, X.; et al. Progress and challenges in maternal health in western China: A Countdown to 2015 national case study. Lancet Glob. Health 2017, 5, e523-e536. [CrossRef]

Publisher's Note: MDPI stays neutral with regard to jurisdictional claims in published maps and institutional affiliations.

(C) 2020 by the authors. Licensee MDPI, Basel, Switzerland. This article is an open access article distributed under the terms and conditions of the Creative Commons Attribution (CC BY) license (http://creativecommons.org/licenses/by/4.0/). 